\title{
Salvage radiation therapy 11 years after a radical prostatectomy
}

\author{
Valérie Hogues; ${ }^{1}$ Carole Lambert, MD; ${ }^{2} \mathrm{MD}$; Michael McCormack, $M D^{3}$ \\ 'Université de Montréal, Montreal, QC, Canada; '2Department of Radiology-Oncology, Université de Montréal, Montreal, QC, Canada; ${ }^{3}$ Department of Surgery, Université de Montréal, Montreal, QC, Canada
}

Cite as: Can Urol Assoc J 2016;10(5-6):E189-91. http://dx.doi.org/10.5489/cuai.3400 Published online May 12, 2016.

\section{Abstract}

We present a patient with a high prostate-specific antigen (PSA) value, who was successfully treated with salvage radiation therapy (RT) 11 years after a radical prostatectomy (RP).

\section{Introduction}

Approximately one in four men will have biochemical recurrence (BCR) after a radical prostatectomy (RP), which is indicative of the presence of residual prostatic epithelial tissue and is presumed to represent cancer. The natural history of clinical progression after BCR is variable. ${ }^{1}$ However according to available data, about $20 \%$ of these patients will die from prostate cancer. ${ }^{2,3}$ As such, there has been considerable research to identify clinically significant markers to determine which patients may benefit from salvage radiation therapy (RT) after BCR. The most important prognostic factor involves giving salvage RT to patients before their prostate-specific antigen (PSA) reaches $1 \mathrm{ng} / \mathrm{ml}$, since half of patients with BCR have a long-term PSA response to RT when treatment is administered early. ${ }^{4}$ Although prognostic markers have been identified, it is not always easy to decide, on an individual basis, if RT is indicated or not and when it should be given. The variable clinical course of these patients leaves much uncertainty about how and when to appropriately manage them. ${ }^{1}$ We present a patient with a high PSA value who was successfully treated with salvage RT 11 years after a RP.

\section{Case report}

A 63-year-old Caucasian man with a medical history of hypertension and dyslipidemia was referred in 2008 by his family doctor for a rising serum prostate-specific antigen (PSA) of $3.9 \mathrm{ng} / \mathrm{mL}$ following a radical prostatectomy (RP) in 1997. The patient had no significant comorbidity and was in good health.
The patient was diagnosed with prostate cancer in 1997 and had undergone sextant transrectal biopsies for a serum PSA of $5.1 \mathrm{ng} / \mathrm{mL}$. Histopathological analysis showed adenocarcinoma with a Gleason score of $5(3+2)$. The number of positive scores was 1 out of 6 . As the digital rectal examination showed no abnormal findings, the clinical stage was T1c NO M0. During the same year, the patient underwent a $\mathrm{RP}$ and the definite pathological analysis revealed Gleason score 4 adenocarcinoma involving approximately $5 \%$ of the gland with negative margins, no capsular invasion, and no seminal vesicle invasion (SVI).

After surgery, the patient did not receive any adjuvant radiation or hormone therapy. He was followed by his family doctor, who performed serum PSAs. The first postoperative serum PSA was done two years after the surgery and was determined to be $1.1 \mathrm{ng} / \mathrm{mL}$. Fig. 1 shows the evolution of the patient's serum PSAs. From June 1999 to October 2004, his PSA went from 1.1 to $2.2 \mathrm{ng} / \mathrm{mL}$. In June 2007, the PSA climbed 3.0 and reached $3.96 \mathrm{ng} / \mathrm{mL}$ in April 2008, at which time the patient was referred for consultation at our institution.

A transrectal ultrasound (TRUS) was performed and biopsies were taken from the prostatic fossa. Pathological analysis confirmed local recurrence with adenocarcinoma Gleason score $7(3+4)$ in $10 \%$ of two of six core biopsies. Digital rectal examination showed no palpable disease. Bone scan and abdominal computed tomography (CT) scan were negative.

The patient was then offered salvage radiotherapy (RT). He received 70 Gy in 35 sessions of 3D external beam radiation therapy to the prostatic fossa using nine coplanar fields with a $25 \mathrm{MV}$ linear accelerator. The treatment took place between August and September 2008. There were no significant acute side effects except mild rectal irritation, relieved with zinc sulfate monohydrate suppositories $\left(\right.$ Anusol $\left.^{\circledR}\right)$. Two months after RT, his PSA had dropped to $1.72 \mathrm{ng} / \mathrm{mL}$ and was still decreasing at last followup, reaching $0.10 \mathrm{ng} / \mathrm{mL}$ 6.5 years after treatment (Fig. 1). Since receiving salvage $\mathrm{RT}$, he has been monitored twice a year by a urologist and a radiation oncologist and has not developed any late side effects or toxicity. 


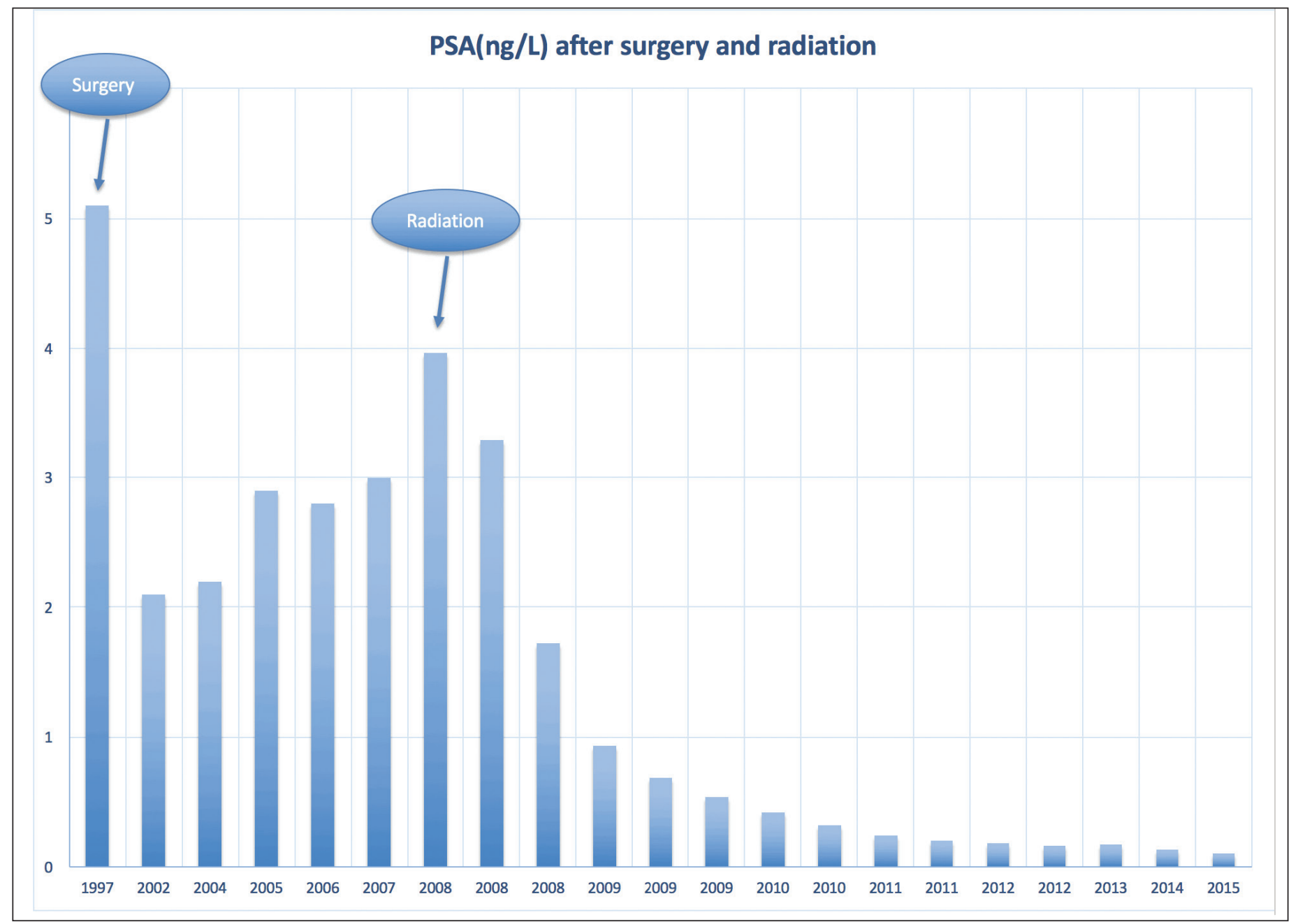

Fig. 1. Evolution of the patient's serum PSA from 1997 to 2015.

\section{Discussion}

Clinical prognostic markers have been identified in order to determine which patients might benefit from salvage RT. A pre-radiation PSA $<1 \mathrm{ng} / \mathrm{mL}$, positive surgical margins, pathological Gleason score $<7$, no SVI, no capsular invasion and a PSA-DT $\geq 11$ months correlate with a durable response to salvage $\mathrm{RT}^{2}$ When patients with these favourable prognostic markers are treated with $\mathrm{RT}$, a four-year recurrence-free probability of $45 \%$ has been reported..$^{2}$ The most important prognostic factor is a PSA $<1 \mathrm{ng} / \mathrm{mL}^{1,2}$ In a recent review, Punnen et al concluded that salvage $\mathrm{RT}$ can provide durable PSA responses in a sizeable percentage of men, especially when given early (i.e., PSA $<1 \mathrm{ng} / \mathrm{ml}$ ). ${ }^{1}$

Our patient had a peculiar history, having been referred to our institution 11 years after a RP with a PSA of $3.9 \mathrm{ng} /$ $\mathrm{mL}$. His low Gleason score may have been an undergrading since, for general pathologists, the main difficulty with the Gleason score system is undergrading. ${ }^{5,6}$ Moreover, the differences between the original Gleason system and the
2005 ISUP Modified Gleason System make it difficult to compare data sets assessing patient outcomes in prostate cancer over time. ${ }^{7}$ Unfortunately, the original pathological tissue was not available for re-evaluation by the pathologist at our institution.

Prostatic fossa biopsies confirmed local recurrence of Gleason 7 prostate cancer. His RP surgical margins were negative, he had no SVI, no capsular invasion, and had an estimated PSA-DT of 4.9 years. He received an appropriate dose of salvage RT (70 Gy) in order to treat his local recurrence. ${ }^{1,8}$

According to the American Urology Association (AUA) guidelines on adjuvant and salvage radiotherapy after prostatectomy, ${ }^{5}$ physicians should offer salvage RT to patients with PSA or local recurrence after RP in whom there is no evidence of distant metastatic disease (Guideline Statement 7). Patients should be informed that the effectiveness of RT for PSA recurrence is greatest when given at lower levels of PSA (Guideline Statement 8). However, this case report illustrates that an elevated PSA is not a contraindication for salvage RT. 
Our patient was referred 11 years after RP with an elevated PSA of $3.96 \mathrm{ng} / \mathrm{mL}$. Even with this unfavourable PSA, considering the very long PSA-DT, salvage RT was discussed with the patient, who then opted to receive treatment for his local recurrence. Following salvage RT, the patient's PSA has decreased continuously over seven years and has now reached $0.10 \mathrm{ng} / \mathrm{mL}$ (Fig. 1). He reports an excellent quality of life with no signs of toxicity. This case illustrates that patients with proven local recurrence and elevated PSA may still benefit from salvage RT many years after a RP, when we take into account the favourable kinetics of a long PSA-DT.

Competing interests: Dr. Lambert has received grants/honoraria from Ferring and has participated in clinical trials for Ferring and Janssen. The remaining authors declare no competing financial or personal interests.

This paper has been peer-reviewed.

\section{References}

1. Punnen $S$, Cooperberg MR, D'Amico AV, et al. Management of biochemical recurrence after primary treatment of prostate cancer: A systematic review of the literature. Eur Urol 2013;64:905-15. http:// dx.doi.org/10.1016/i.eururo.2013.05.025

2. Simmons MN, Stephenson AJ, Klein EA. Natural history of biochemical recurrence after radical prostatectomy: Risk assessment for secondary therapy. Eur Urol 2007;51:1 175-84. http://dx.doi.org/10.1016/i. eururo.2007.01.015

3. Han M, Partin AW, Zahurak M, et al. Biochemical (prostate-specific antigen) recurrence probability following radical prostatectomy for clinically localized prostate cancer. J Urol 2003;169:517-23. http://dx.doi. org/10.1016/S0022-5347(05)63946-8

4. Stephenson AJ, Scardino PT, Kattan MW, et al. Predicting the outcome of salvage radiation therapy for recurrent prostate cancer after radical prostatectomy. J Clin Oncol 2007;25:2035-41. http://dx.doi. org/10.1200/JC0.2006.08.9607

5. Thompson IM, Valicenti R, Albertsen PC, et al. Adjuvant and salvage radiotherapy after prostatectomy: ASTRO/AUA guideline. https://www.auanet.org/common/pdf/education/clinical-guidance/RadiationAfter-Prostatectomy.pdf. Accessed April 7, 2016.

6. Allsbrook Jr WC, Mangold A, Johnson MH, et al. Interobserver reproducibility of Gleason grading of prostatic carcinoma. General pathologist. Hum Pathol 2001;32:81-8. http://dx.doi.org/10.1053/ hupa.2001.21135

7. Humphrey PA. Gleason grading and prognostic factors in carcinoma of the prostate. Modern Pathology 2004;17 :292-306. http://dx.doi.org/10.1038/modpathol.3800054

8. King CR. The timing of salvage radiotherapy after radical prostatectomy: A systematic review. Int I Radiat Oncol Biol Phys 2012;84:104-11. hittp://dx.doi.org/10.1016/i.ijrobp.2011.10.069

Correspondence: Dr. Michael McCormack, Department of Surgery, Université de Montréal, Montreal, QC, Canada; mm@urol.ca 